\section{The MRCPSYCH examinations}

In the June 1988 issue of the Bulletin (112), several articles relating to the examinations appeared under the section, Trainees Forum.

We would like to draw your attention to two inaccuracies:

1. Drs Armstrong and Loosmore's article 'How to run the MRCPsych Part II Examination' (p 229) refers to the clinical and oral section of the examination. It states that the examination includes a viva lasting 15 minutes.

This information is incorrect. The PMP Oral Section of the MRCPsych Part II lasts 30 minutes.
2. Dr O. Daly's article 'The Membership Examination-One Candidate's View Point' (p 231) makes a reference to a variable percentage contribution of marks from each section of the Examination.

In fact the four parts of the Membership Examination (MCQ, Essay, Clinical and Oral) have equal weight in terms of marks. Although candidates must pass the Clinical Examination, the other three parts should be seen as complementary rather than secondary to it.

Professor A. C. P. Sims, Dean

Professor H. G. Morgan, Chief Examiner

\title{
Obituary
}

\section{Editor: Henry R. Rollin}

Vojtech Adalbert Kral, Professor Emeritus of Clinical Psychiatry, University of Western Ontario, Canada.

Dr Vojtech Adalbert Kral, a distinguished Canadian psychiatrist and pioneer of psychogeriatrics, known to his family and friends as Bertie, died on 6 June, 1988 during a visit to Israel.

Dr Kral was born on 5 February, 1903 in what is now Czechoslovakia and received his education in the German-speaking state high school (Gymnasium) in Prague and at the German University of Prague, graduating MD in March 1927. He studied further with the leaders of psychiatry and neurology in Vienna, Zurich, and Munich and, from 1935 to 1938, was a privat-dozent, corresponding to an Associate Professor, in the Department of Neurology and Psychiatry at his alma mater.

He and his wife, Katherine, (née Neumark), an ophthalmologist, as Jews, were both imprisoned in Theresienstadt Concentration Camp throughout the Nazi period. There, he participated in the medical care of the prisoners and he and his wife were saved from deportation to Auschwitz and extermination because of the Nazi need for an expert opinion on an outbreak of encephalitis amongst prisoners which might have affected the staff. He subsequently described this epidemic in 1947 in the Journal of Nervous and Mental Diseases, as well as in a Czech journal.
Following their liberation, the Krals returned to Czechoslovakia but, after the Communist takeover, they fled to Canada. From 1952 to 1972 , he served first as lecturer and ultimately as Associate Professor at McGill University, having achieved specialist certification in both neurology and psychiatry in Canada. Thereafter, he moved to London, Ontario, and continued to work and teach psychogeriatrics.

Dr Kral published some 180 papers or chapters of books on scientific topics. His initial studies were on the biochemistry of the cerebrospinal fluid in different illnesses of the nervous system. From 1933 onwards, he studied memory function in such disorders. In 1956, he described benign senescent forgetfulness as a common phenomenon of the elderly, not to be confused with dementing illnesses like Alzheimer's disease. His recognition of this harmless syndrome was widely appreciated and helped to reassure many ageing individuals. He undertook further studies on Alzheimer's disease, neurotropic medication, and pseudo-dementia of the aged.

Dr Kral received the Allan Award and Gold Medal of the American Geriatric Society, as well as an honorary award from the Ontario Psychogeriatric Association and the annual award of the Psychiatric Out-patients Center of America. He was elected a Fellow of the British Royal College of Psychiatrists and a Fellow of the American Psychiatric Associ- 